\title{
Varlık Yönetiminde Ray ve Tekerlek Etkileşimi Öncül Değerlendirmesi
}

\author{
Pelin BOYACIOĞLU
}

Imperial College London, Civil and Environmental Engineering Department, SW7 2AZ, London, United Kingdom

p.boyacioglu@imperial.ac.uk

(Alınıs/Received: 17.11.2021, Kabul/Accepted: 25.01.2022, Yayımlama/Published: 31.01.2022)

\begin{abstract}
Öz: Demiryollarında varlık yönetimi daha güvenilir ve az maliyetli hizmet sunulabilmek amacıyla alt sistemlerde yer alan tüm bileşen ve malzemelerin ömür maliyetlerini incelemektedir. Böylelikle, varlıkların tasarım ve yapım süreçlerinden başlayarak işletme, bakım ve tasfiye aşamaları en etkili şekilde planlanması ve sürdürülmesiyle ilgilenmektedir.
\end{abstract}

Varlık yönetimi altında ray ve tekerlek etkileşimi detaylı simülasyon ve modelleme yöntemleri kullanılarak uygun profil ve malzeme seçimi ve bakım sürelerinin incelenmesi ile ömür maliyetlerinin azaltılması amaçlanmaktadır. Bu tür çalışmalar ilave zaman ve maliyet gerektireceği için öncellikle ray-tekerlek arayüzünde meydana gelen temas noktası parametrelerinin incelenip hasar ve aşınma durumlarına olan yatkınlıklıkları öncül değerlendirmede ele alınmalıdır.

Bu çalışmada Avrupa'daki bir Altyapı Yöneticisi'ne ait ray ve tekerlek profillerinin tasarım (yeni) ve işletme altındaki (aşınmış) durumları incelenip ray-tekerlek temas analizleri gerçekleştirilmiştir. İlk adımda işletme altında aşınmış profillerde yaşanan değişimler gösterilirken sonraki adımlarda temas analizi parametreleri yeni durumdaki değerlerle karşılaştırılmıştır. Hesaplanan öncül temas analizleri sırasıyla yuvarlanma yarıçapı farklılıkları, eşdeğer koniklik, temas noktası ve ilgili parametreleri kapsamıştır. Hem profil analizi hem de yuvarlanma yarıçapı farklılıkları, ray-tekerlek etkileşiminde ani buden temasının gerçekleşebileceğini ve bu durumun aşınma ve hasara yatkınlığı arttırabileceğini göstermiştir. Yeni profil durumunun işletmede seçilen 130 ve 653 m yarıçaplı kurplardaki durumlara oranla daha yatkın olduğu gözlemlenmiştir. $\mathrm{Bu}$ durumun yeni profillerde aşınma ve hasar oluşumlarını hızlandırabileceği fakat, işletme altında profillerde yaşanan değişimlerle daha konformal temas oluşabileceği ve böylelikle varlıkların ömürlerinin artabileceği söylenebilir.

Anahtar kelimeler: Varlık Yönetimi, Ray-Tekerlek Teması, Raylı Araçları Dinamiği, Ray-Tekerlek Aşınma ve Hasarları.

\section{Preliminary Analysis of Wheel-Rail Interaction in the Asset Management}

Abstract: Asset management in railways examines the lifecycle costs of components and materials in all the subsystems in order to provide reliable and cost-efficient services. Therefore, it is interested in effective planning and management of the assests starting from the design and construction stages to the operation, maintenance and disposal stages.

Examination of rail and wheel interaction under asset management is conducted using detailed simulations and modelling to select a suitable profile and material and analyse maintenance intervals aiming to reduce its lifecycle costs. However, this type of investigations may require additional time and costs. Therefore, preliminary analysis should be carried out to analyse the parameters generated at the wheel-rail interface and their susceptibility to wear and cracking.

In this study, the rail and wheel profiles under the design (new) and operation (worn) conditions were examined and wheel-rail contact analysis was conducted which are used by an Infrastructure Manager in Europe. In the first step, the changes in the worn profiles during the operations were presented and the contact parameters were compared with the new condition in the subsequent steps. The preliminary contact 
analysis covered the rolling radius difference, equivalent conicity, contact postion and related parameters. Both the analysis of profiles and rolling radius differences showed the sudden flange contact generation and the wear and cracking susceptibility at the wheel-rail interaction. In comparison to operation which are shown by the use of profiles under $130 \mathrm{~m}$ and $653 \mathrm{~m}$ radii curves, the new profiles seemed to be more vulnerable. This may fasten the generation of wear and cracking in the early stages, but, the changes in the worn profiles during the operation may produce more conformal contacts which may in turn potentially help to increase the assets life.

Keywords: Asset Management, Rail-Wheel Contact, Rolling Vehicle Dynamics, Rail-Wheel Wear and Cracking.

\section{Giriş}

Demiryollarında varlık yönetimi daha güvenilir ve az maliyetli hizmet sunulabilmek amacıyla alt sistemlerdeki; hat işleri, istasyon, sinyalizasyon, telekomünikasyon ve tren dizileri vs.'de yer alan tüm bileşen ve malzemelerin ömür maliyetlerini incelemektedir. Böylelikle, varlıkların fiziksel olarak değerlendirilmesinin yanında tasarım ve yapım süreçlerinden başlayarak işletme, bakım ve tasfiye aşamalarının da en etkili şekilde planlanması ve sürdürülmesiyle ilgilenmektedir.

Ray ve tekerlek etkileşiminin varlık yönetimi altında incelenmesi; uygun profil ve malzeme seçimi, bakım sürelerinin optimizasyonu gibi çeşitli detaylı analizlerle ömür maliyetlerinin azaltılmasını amaçlamaktadır. Ray-tekerlek arayüzünde meydana gelen temas yüzeyi, tren hareketinde önemli bir yere sahip olup, ağır yüklere maruz kalmaktadır. Ağır yükler ve geçiş sayılarının artmasıyla beraber ray ve tekerlek malzemelerinde yorulmalar, daha sonrasında aşınma ve çeşitli hasarlar görülmektedir. Bu sebeple tasarımdan itibaren ray-tekerlek etkileşimi optimum şekilde planlanmalı, işletme ve bakım aşamalarında karşılaşılabilecek durumlar önceden tahmin edilip yönetilmelidır. Etkin planlama, tahmin ve yönetim, güvenliğin artırılmasına, yaşanabilecek aksaklıkların (gecikmeler vb.) ve gider maliyetlerinin azaltılmasına yardımcı olacaktır. Fakat, bu çalışmaların detaylı simülasyon ve analizlerle yapılabileceği ve ilave zaman ve maliyet gerektireceği de unutulmamalıdır. Bu sebeple, öncül değerlendirme yöntemleri olan profil ve temas noktası analizleri yapılmalı ve hasar ve aşınma durumlarına olan yatkınlık gösterildikten sonra detaylı çalışma gereksinimine karar verilmelidir.

Literatürde detaylı tren araç dinamiği simülasyonları kullanılarak ray-tekerlek etkileşimi ve hasar ve aşınma tahminleri ile ilgili yapılan çeşitli çalışmalar yer almaktadır. Örneğin, ray ve tekerlek üst ve alt yüzeylerindeki hasar oluşumlarına etki eden ana faktörler dikkate alınarak farklı modeller üretilmiştir [1]. Bir diğer çalışmada ise hasar büyümesi tahmin modelleri kullanılarak gerçek ray ve tekerlekte yaşanan durumlar karşılaştırılmıştır [2]. Aşınmalarla ilgili olarak da çesitli modeller yer almakta olup en önemlilerinden birisi olan Archard modeli kullanılarak aşınmalara bağlı tekerlek profilindeki gerçekleşebilecek değişimler tahmin edilmiş ve saha ölçümleriyle karşılaştırılmıştır [3]. Ray aşınmaları ve özellikle de ekartman köşesinde sıklıkla meydana gelen durumlarla ilgili olarak da optimum ray profili oluşturulmaya çalışılmaktadır [4].

Bu çalışmada Avrupa'daki bir Altyapı Yöneticisi'ne ait ray ve tekerlek profilleri tasarım (yeni) ve işletme altındaki (aşınmış) durumları incelendikten sonra ray ve tekerlek temas noktası analizleri gösterilmiştir. Öncül değerlendirmede sırasıyla yuvarlanma yarıçapı farklılıkları, eşdeğer koniklik, temas noktası ve ilgili parametreler hesaplanmıştır. Yeni ve aşınmış durumdaki bulunan sonuçların hasar ve aşınmaya olan etkisi değerlendirilmiştir.

\section{Tasarım ve İşletme durumlarındaki Ray ve Tekerlek Profilleri Analizi}

Avrupa Altyapı Yöneticisi, CEN 54E1 çelik malzemesi ve 1:40 eğikliğinde ray profili ile mevcuttaki elektrikli tren setlerine uygun olarak tasarlanmış tekerlek profili kullanmaktadır. 
Ray döşenmesi ve tekerlek tornalaması zamanlamalarındaki farklılıklar ve aşınma oranlarında görülen değişiklikler sebebiyle gerçek durumda çok farklı ray ve tekerlek profilleri mevcuttur. Örneğin, eş zamanlarda döşenmiş aliyman ve kurp bölgelerinde yer alan iki ray, farklı aşınmalara ve profil şekillerine sahip olabilirler. İlgili çalışmalar kurp bölgelerinde oluşan temas yüzeylerinin daha fazla yüklere maruz kalmasıyla, özellikle de yatay doğrultudaki kuvvetlerde artı̧s sebebiyle aşınma oranlarının aliyman hatlara göre daha fazla olduğunu göstermiştir [5-7]. Gerçekte yaşanan bu farklılıkları gözlemlemek amacıyla analizde farklı seviyelerde aşınmış ray ve tekerlek profilleri seçilmiştir.

Şekil 1'de yeni CEN 54E1 profili ile saha ölçümlerinden alınan aşınmış ray profilleri yer almaktadır. Demiryollarında kurplu hatlarda dever tek raya uygulanmaktadır, kotun daha fazla olduğu tarafa yüksek/dış ray olarak tanımlanırken, kotun aynı kaldığı tarafa düşük/iç ray denilmektedir. Sağ kurpta yüksek/dış ray Şekil 1.a'da yer alırken, düşük/iç ray Şekil 1.b'de yer almaktadır, sol kurpta ise bu durumun tam tersi geçerli olup düşük ray Şekil 1.c'de verilirken yüksek ray Şekil 1.d'de görülmektedir. Kurp bölgelerinde tren dinamik performansında sapma açısındaki artış sebebiyle tekerlekler çoğunlukla yüksek rayın (Şekil 1.a ve Şekil 1.d) ekartman köşesine temas ettikleri için bu alanda daha fazla aşınmalara neden olmaktadır. Şekil 1.b ve Şekil 1.c'de verilen düşük raylarda taç bölgesinde oluşan temas yüzeyleri bu alandaki aşınmaları meydana getirmişlerdir. Çalışmada ray döşeme tarihleri verilmemesine karşın, yukarıda da belirtildiği üzere aşınma oranı ve kurp yarıçapı araşındaki ters orantı bu durumda da gözükmekte olup, 130 m yarıçaplı kurptaki (Şekil 1.a) yüksek ray, 653 m yarıçaplı kurptaki (Şekil 1.d) ray ile karşılaştırıldığında yanal aşınmaların özellikle daha geniş alana yayıldığı ve miktarının daha fazla olduğu görülmektedir.

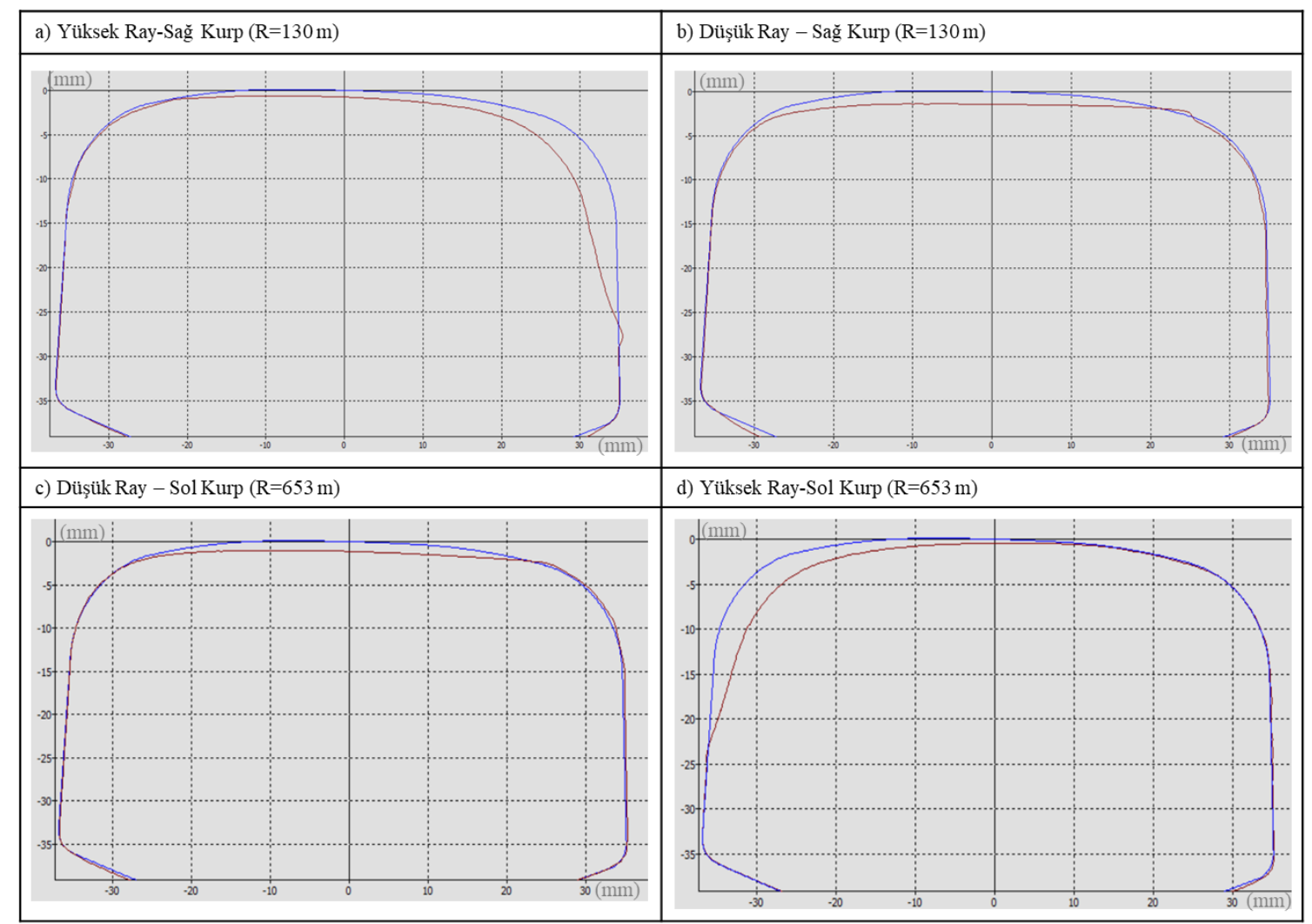

Şekil 1. 130 ve 653 m yarıçaplı kurplarda ray aşınma durumları (mavi: yeni ve kırmızı: aşınmıș /saha ölçüm profilleri) 
Şekil 2'de yeni tekerlek profili ile tornalama öncesi yapılan ölçüm profilleri verilmektedir. Yeni profil (mavi) ile oluşan değişimlere bakıldığında (kırmızı ve yeşil) profillerdeki aşınmaların çoğunlukla tekerleklerin buden yüzü ve taban kısımlarında oluştuğu görülmektedir. Bu durum ilave verilen çizimlerden de görüleceği üzere tekerlek ve ray temasının daha çok kurp bölgelerinde iki noktada gerçekleştiği olasılığını göstermektedir. İkili (konformal olmayan) temasta, yüzey alanlarının daha küçük olmasıyla hem gerilmeler, hem de aşınma oranları daha fazla olabilmektedir. Buden kökünde oluşan konformal temas durumunda ise yüzey alanının daha geniş olması hem gerilmelerin hem de aşınma oranlarının azalmasına neden olmaktadır. Buden arkasında ve dış kısımda oluşan aşınmalar makas bölgelerinde kontray ve tavşanayağında temasların oluştuğunu işaret etmektedir.

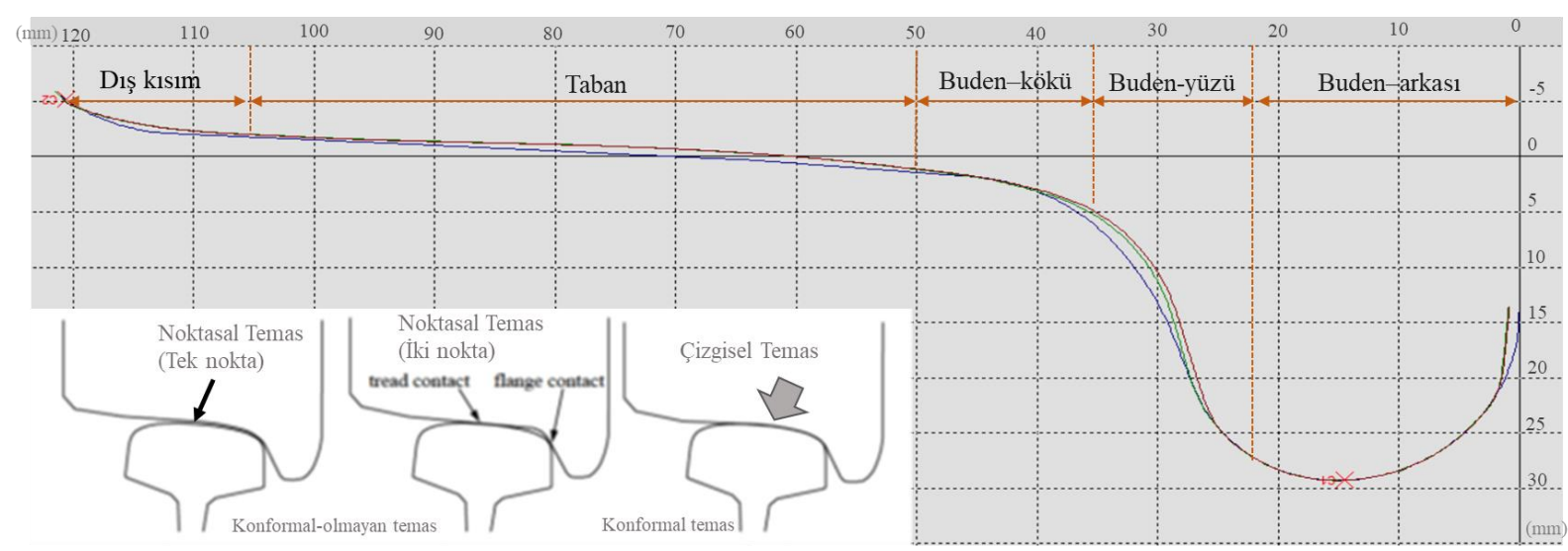

Şekil 2. Tasarım-yeni (mavi) ve aşınmış (kırmızı ve yeşil) tekerlek profillerindeki değişim

\section{Metot - Öncül Değerlendirmede Ray-Tekerlek Temas Analizleri}

Tasarım ve işletmedeki ray-tekerlek temas koşullarındaki değişimleri ve bunların aşınmaya yaptığı etkileri gösterebilmek amacıyla EN 15302:2008 [8] standartında verilen eşdeğer koniklik ve Hertzian teorisi [9] temas formülleri yardımıyla öncül analizler gerçekleştirilmiştir.

Ray ve tekerlek profilleri ile ray açıklığı, ray eğimi, aks yükü, tekerlek çapı, iç açıklık bilgileri kullanılarak farklı yatay yer değiştirme durumlarında temas analizleri yapılmıştır. Yuvarlanma yarıçapı farklılıkları, eşdeğer koniklik, temas noktaları, yüzey alanları ve diğer ilgili parametreler hesaplanmıştır. Ray-tekerlek temas uygunluğununun anlaşılmasına yardımc1 olacak bu hesaplamalar aşınma ve hasar koşullarına yatkınlık ile ilgili de işaretler verebilmektedir.

Tren araç dinamiğinde en önemli etkenlerden birisi de içteki tekerlek ve dıştaki tekerleğin farklı mesafelerde yol kat edebilmesi için tasarlanan yuvarlanma yarıçapı farklılığıdır. Ray (dairesel) ve tekerlek (konik) profilleri şekillerine bağlı olarak temas noktaları üzerinde farklı yuvarlanma yarıçapları oluşmaktadır. Şekil 3'de görüleceği üzere, $y$ yatay yerdeğiştirmesi altında sol $\left(r_{s o l}\right)$ ve sağ $\left(r_{s a \breve{g}}\right)$ yuvarlanma yarıçapları meydana gelmektedir. Burada $r_{0}$ nominal tekerlek yarıçap1 iken, $l_{0}$ ray temas noktaları arasındaki uzaklığın yarısı ve $\gamma$ konikliktir. Sol ve sağ yuvarlanma yarıçaplarındaki $\gamma$ eğimin küçük olması sebebiyle birimi ihmal edilebilinirken $\Delta r$ yuvarlanma yarıçapı farklılığı sol ve sağ yuvarlanma yarıçapları arasındaki farktır. Kurplu hatlarda uygulanan deverin de etkisiyle yuvarlanma yarıçapı farklılığı aliymanli hatlara göre daha büyüktür. 


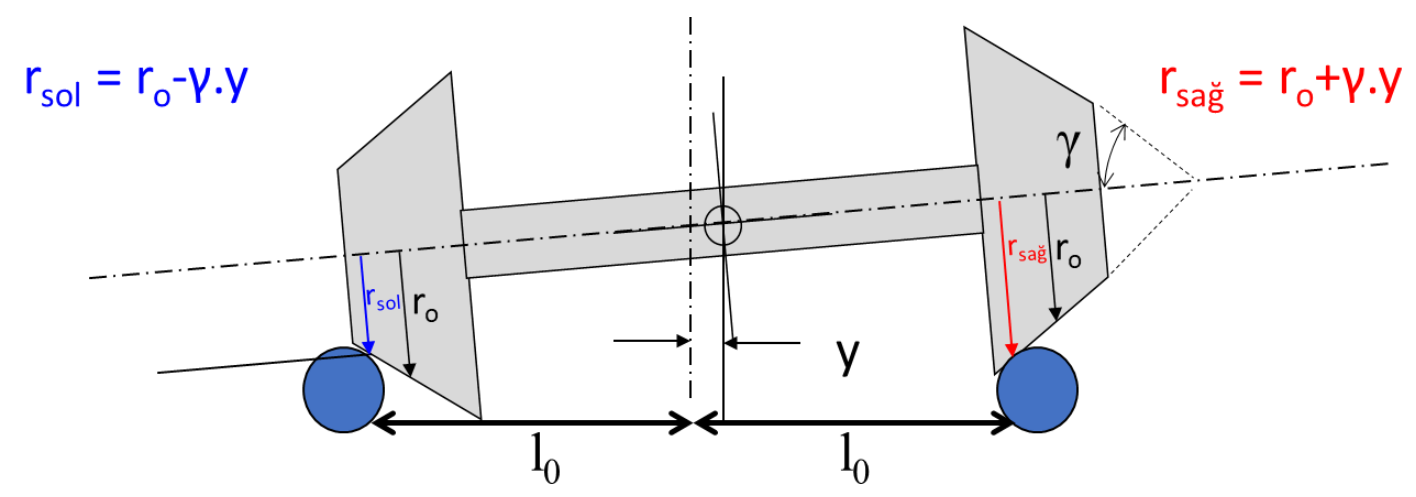

Şekil 3. Sol ve sağ tekerlekteki yuvarlanma yarıçapları

Koniklik aşağıdaki verilen formül yardımıyla bulunur.

$$
\gamma=\frac{r_{s o l}-r_{s a \breve{s}}}{2 y}=\frac{\Delta r}{2 y}
$$

Eşdeğer koniklik $\gamma_{e}$, belirli bir yanal yer değiştirme altında belirlenip, $\Delta r(y)$ doğrusal bir fonksiyon olarak ele alınmaktadır.

Ray ve tekerlek etkileşimindeki yükler ise aralarında oluşan temas yüzeylerine etki etmektedir. Literatür'de yaygın olarak kullanılan Hertzian teorisinde düşey yükler altında ellipsoit biçiminde temas yüzeyinin oluştuğu varsayımıyla ve Şekil 4'de verilen $a$ boylamsal, $b$ yanal genişlik ile $P_{m}$ maksimum basınç/gerilim değerleri hesaplanabilmektedir. [10].



Şekil 4: Hertzian teorisi’nde ray-tekerlek temas yüzeyi

Hertzian teorisi'ndeki diğer varsayımlar ve ilgili parametrelerin daha detaylı denklemleri çeşitli kaynaklarda verilmektedir [10]. Çalışmada temas boyutları $(a, b)$ aşağıda verilen denklemler (2- 
3) kullanılarak hesaplanmıştır [11]. Formüllerdeki m ve n katsayıları tablolar kullanılarak bulunurken, A ve B sırasıyla boylamsal ve yanal eğrilik, $\mathrm{N}$ düşey yük ve $\mathrm{E}$ elastisite modülüdür.

$$
\begin{gathered}
a=m \sqrt[3]{\left(\frac{3 N\left(1-\vartheta^{2}\right)}{E(A+B)}\right.} \\
b=n \sqrt[3]{\left(\frac{3 N\left(1-\vartheta^{2}\right)}{E(A+B)}\right.}
\end{gathered}
$$

Temas alani (A) ise elips olması sebebiyle 4. Denklem yardımı ile bulunurken ve maksimum basınç $P_{m}$ 5. Denklem kullanılarak hesaplanmıştır.

$$
\begin{gathered}
A=\pi a b \\
P_{m}=\frac{3 N}{2 \pi a b}
\end{gathered}
$$

\section{Bulgular}

Çalışmada, öncül ray-tekerlek temas analizi yuvarlanma yarıçapı farklılıkları, eşdeğer koniklik, temas noktaları ve ilgili diğer parametrelerce hesaplanmış ve sırasıyla verilmiştir.

\subsection{Yuvarlanma yarıçapı farklılıkları}

Sağ ve sol tekerleklerin belirli yanal yer değiştirmeler altında oluşan yuvarlanma yarıçapı farklılıkları (YYF), meydana gelen eşdeğer koniklik hakkında ipuçları verebilmektedir. Genel anlamda, YYF doğrusunun eğimindeki artış konikliği de arttırmaktadır. Daha yüksek eğim değeri, önceki bölümde de bahsedilen daha konformal temasın göstergesi iken, daha düşük YYF doğru eğimi konformal olmayan temasa yatkınlığı meydana getirmektedir. YYF'deki ani artışlar da temas noktalarının hangi yanal yer değiştirmeler altında tekerlek tabanı temasından buden temasına geçtiği hakkında bilgi vermektedir.

Şekil 5'de yeni durumdaki CEN 54E1 (1:40) ray ile tekerlek profillerinin $-10 \mathrm{~mm}$ ile $+10 \mathrm{~mm}$ arasındaki yanal yerdeğiştirmeler altında oluşan YYF değerleri verilmektedır. Farklı tekerlek iç açıklıkları etkilerini sunabilmek amacıyla $1525 \mathrm{~mm}$ nominal değer ile işletmede izin verilen 1521 mm minimum ve 1526 maksimum limit değerleri altında meydana gelen YYF'ler de gösterilmektedir. YYF doğruları 0 noktasından itibaren incelendiğinde eğimlerin kısmen daha düşük olduğu ve bu sebeple ani artışların meydana geldiği gözükmektedır. Bu durum, $y= \pm 6.30$ mm'den daha düşük yanal yer değiştirmeler altında tek taban temas koşullarının oluşabileceğini göstermektedir. Bu noktadaki (ani atlama) buden geçişi olarak değerlendirilmekte ve hem taban hem de buden bölgesinde iki noktalı temasın oluştuğunu işaret etmektedir. Daha büyük yanal yer değiştirmelerde geçiş tamamlanır ve buden yüzeyinde tek noktada temas yüzeyi oluşur. Tekerlek iç açıklığ nominal $(1525 \mathrm{~mm})$ değerden, minimum $(1521 \mathrm{~mm})$ limite düştüğünde, buden yüzeyindeki temas geçişi daha büyük bir yanal yer değiştirmede $(\mathrm{y}= \pm 8.2 \mathrm{~mm})$ gerçekleşirken, maksimum $(1526 \mathrm{~mm})$ limit değerinde daha küçük değerlerde $(\mathrm{y}= \pm 5.9 \mathrm{~mm})$ meydana gelir. Hem sol hem de sağ tarafta benzer tekerlek ray profilleri kullanıldığında, $y=0$ mm'ye göre simetrik YYF doğruları elde edilmektedir. Bu durum, $\mathrm{y}=+6.3 \mathrm{~mm}$ 'de sol yönlü kurpta yüksek ray (sağ taraf) üzerinde oluşan buden temasını gösterirken, $y=-6.3 \mathrm{~mm}$ 'de sağ yönlü kurpta yüksek rayda (sol taraf) meydana gelen buden temasını göstermektedir. 


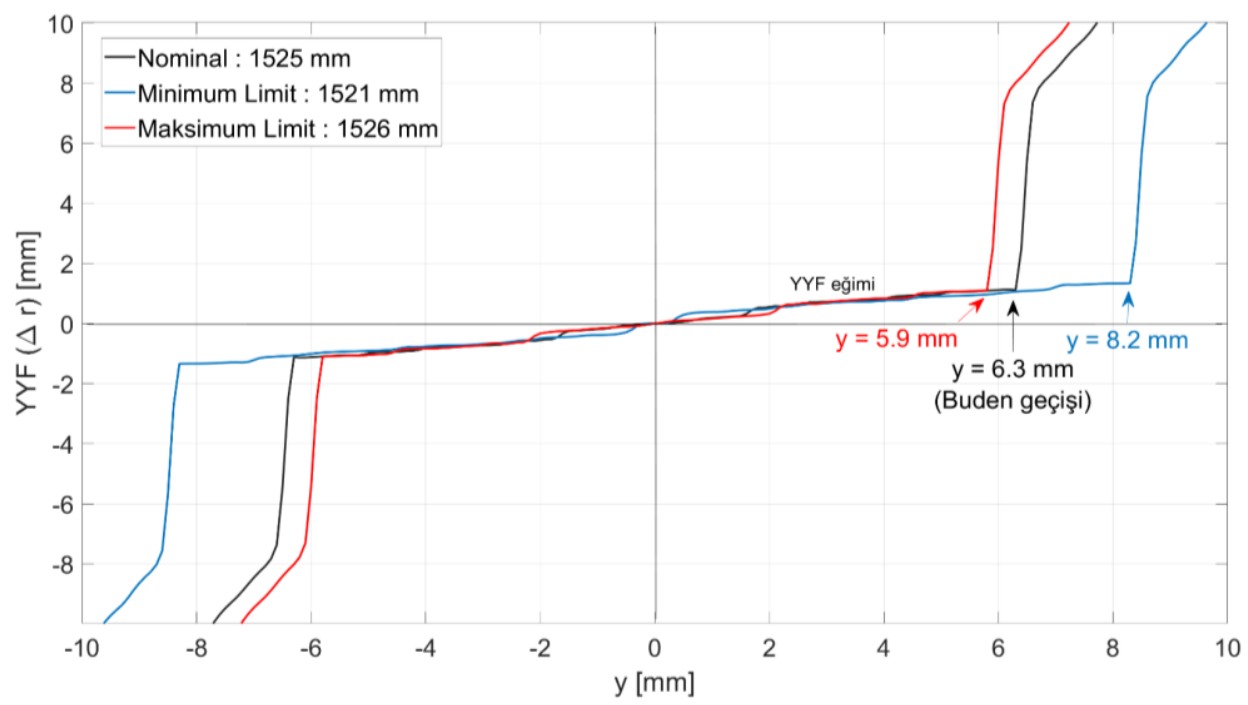

Şekil 5. Yeni durumdaki CEN 54E1 (1:40) ray ile tekerlek profillerinin YYF değerlerinin farklı iç açıklıklar altında karşılaştırılması

İşletme durumundaki ray-tekerlek etkileşimi değişimlerini gösterebilmek amacıyla Şekil 6 ve Şekil 7 hazırlanmıştır. Sırasıyla $130 \mathrm{~m}$ yarıçaplı sağ kurp ve $653 \mathrm{~m}$ yarıçaplı sol kurptaki raylardan alınan ölçüm profilleri ile yeni ve işletme altındaki aşınmış tekerlek profilleri arasında oluşan YYF'ler Şekil 6 ve Şekil 7'de verilmektedir. Depo bakımlarındaki tekerlek iç açıklığı verilerinin incelenmesi sonucunda en yaygın $1522.5 \mathrm{~mm}$ olduğu ve yukarıda verilen limit değerlerin içerisinde kaldığı görülmüştür.

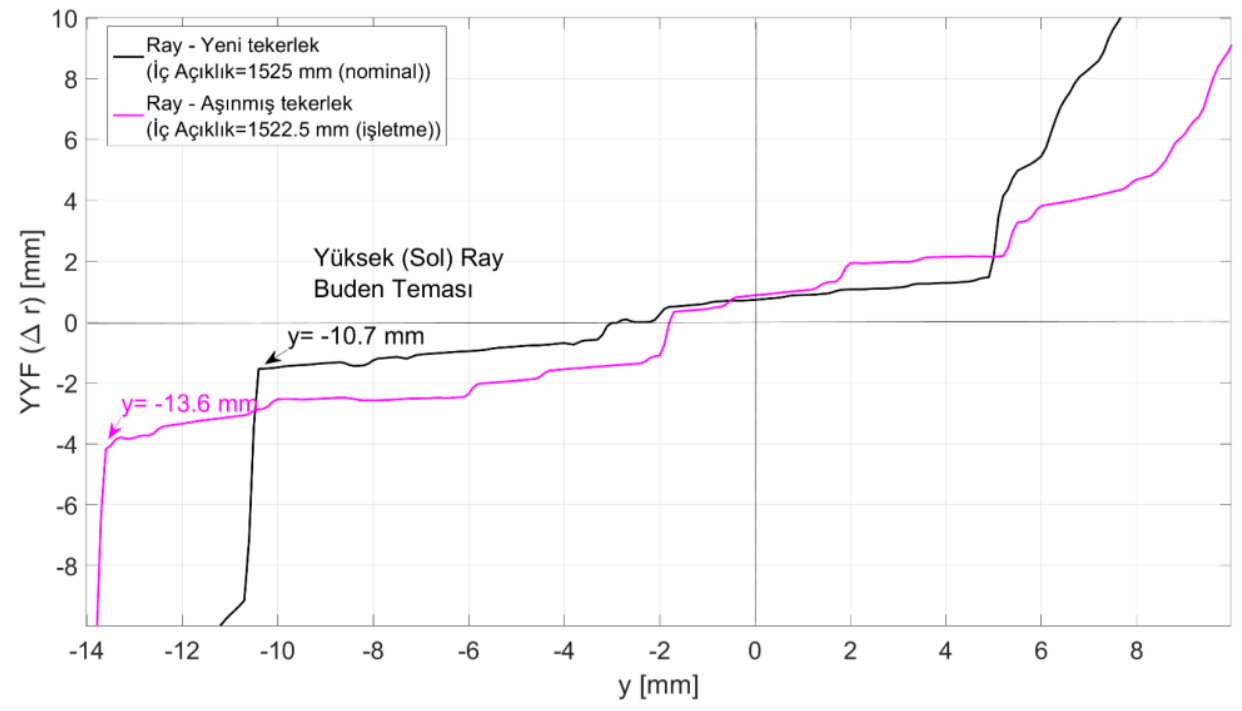

Şekil 6. Yeni ve aşınmış tekerlek profilleri ile $130 \mathrm{~m}$ yarıçaplı sağ yönlü kurp bölgesindeki ray profili altında oluşan YYF değerleri 


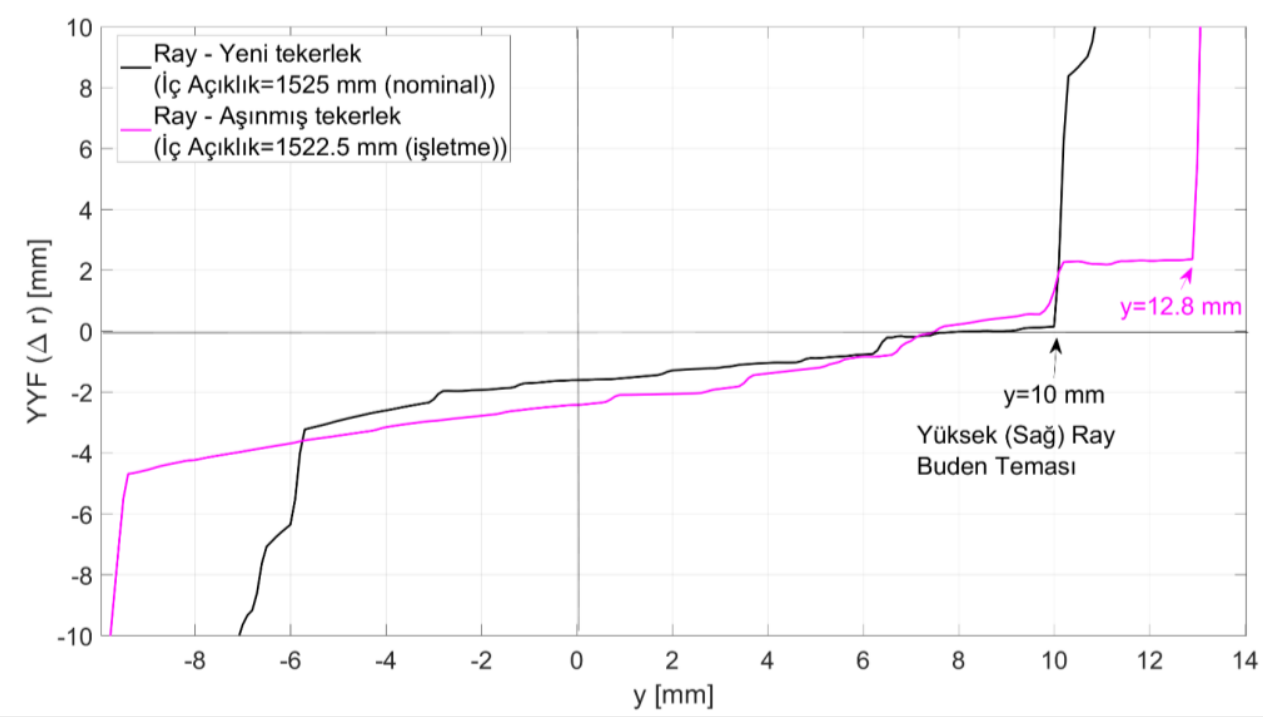

Şekil 7. Yeni ve aşınmış tekerlek profilleri ile $653 \mathrm{~m}$ yarıçaplı sol yönlü kurp bölgesindeki ray profili altında oluşan YYF değerleri

Raylarda ve tekerleklerde yaşanan aşınmalar ekartman açıklığının artmasına ve temas noktalarının tasarım durumuna göre ötelenmesine sebep olmuştur. Böylelikle, yeni durumda $y=$ $\pm 6.30 \mathrm{~mm}$ 'de meydana gelen buden yüzeyi başlangıç temas noktası aşınmış tekerlek altında sol tarafta yer alan yüksek rayda ( $R=130 \mathrm{~m}$ sağ kurp) $\mathrm{y}=-13,6 \mathrm{~mm}$ noktasına ilerlerken, sağ tarafta yer alan yüksek rayda $(\mathrm{R}=653 \mathrm{~m}$ sol kurp) $\mathrm{y}=+12,8 \mathrm{~mm}$ yanal yer değiştirme noktasında oluşmuştur.

İşletme altında YYF doğrularındaki eğimin yeni tasarım durumuna oranla daha fazla olduğu gözlemlenirken tekerlek tabanından buden yüzeyine hızlı geçişi temsil eden ani artışın işletme durumunda da oluşabileceği söylenebilir. Bu durum, tasarım profillerinde meydana gelebilecek hızlı hasar ve aşınmaların işletme altında yavaşlamasına ve varlıkların ömür sürelerinin artmasına sebep olabilmektedir.

\subsection{Eşdeğer koniklik}

Tasarım ve işletme altındaki aşınmış ray ve tekerlek profilleri altında oluşan eşdeğer koniklik ilgili EN 15302:2008 [8] standartında verilen formüller kullanılarak hesaplanmış ve elde edilen değerler Tablo 1'de karşılaştırılmıştır. Yukarıda YYF grafiklerinden beklenildiği üzere, yeni durumdaki eşdeğer koniklik, aşınmış durumdaki değerlere oranla fazlasıyla düşük kalmaktadır. Aşınmadaki büyümeyle beraber eşdeğer koniklik $653 \mathrm{~m}$ yarıçaplı kurpta 0.27 olurken $130 \mathrm{~m}$ yarıçaplı kurpta 0.29 seviyesine çıktı̆̆ hesaplanmıştır.

Tablo 1. Yeni ve aşınmış ray ve tekerlek profilleri altında oluşan eşdeğer koniklik değerleri

\begin{tabular}{ccc}
\hline \multirow{2}{*}{ Yeni ray - tekerlek } & \multicolumn{2}{c}{ Aşınmış ray ve tekerlek } \\
\cline { 2 - 3 } & $\mathrm{R}=130$ m kurptaki ray & $\mathrm{R}=653$ m kurptaki ray \\
\hline 0.12 & 0.29 & 0.27 \\
\hline
\end{tabular}

\subsection{Temas noktalart}

Farklı yanal yer değiştirmeler altında olası temas konumlarını göstermek amacıyla, yeni ve aşınmış ray-tekerlek profilleri kullanılarak Şekil 8'de verilen temas noktası grafikleri hazırlanmıştır. 
Yukarıda verilen YYF grafiklerinden beklenildiği üzere, yeni tekerlek profili altında rayların ekartman köşesinde temas noktasının bulunmaması ve daha çok etkileşimin tepe noktası ile yanak bölgelerinde oluşması, konformal olmayan iki noktalı temasa yatkınlığı göstermektedir. Şekil 8.c'de verilen $653 \mathrm{~m}$ yarıçaplı kurp bölgesinde aşınmanın daha az olması sebebiyle yüksek (sağ) ray üzerinde de açıkça görülebilir. Fakat, Şekil 8.b'de verilen $130 \mathrm{~m}$ yarıçaplı kurp üzerinde ray tepe bölgesinde oluşan temas noktalarının daha geniş bir alana etki ettiği görülmektedır. Tekerlek buden temasının hangi yanal yerdeğiştime de meydana geldiği de Şekil 8'de verilmektedir. Örneğin, $653 \mathrm{~m}$ yarıçaplı sol kurpta $12.8 \mathrm{~mm}$ yanal yerdeğiştirmede oluşurken, $130 \mathrm{~m}$ yarıçaplı sağ kurp üzerinde -13.6 mm'de meydana gelmektedir.

a) Yeni Ray - Tekerlek

Ekartman Uzunluğu: $1600 \mathrm{~mm}$ İç Aç1klık= $1525 \mathrm{~mm}$

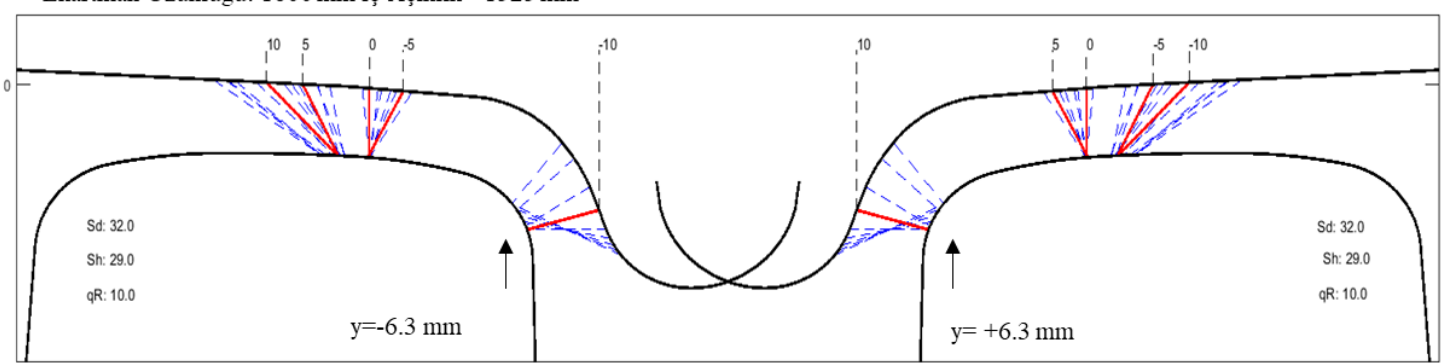

b) $\mathrm{R}=130 \mathrm{~m}$ kurptaki ray - Așınmıș tekerlek

b) Ekartman Uzunluğu: $1600 \mathrm{~mm}$ İç Açılklı $=1522.5 \mathrm{~mm}$

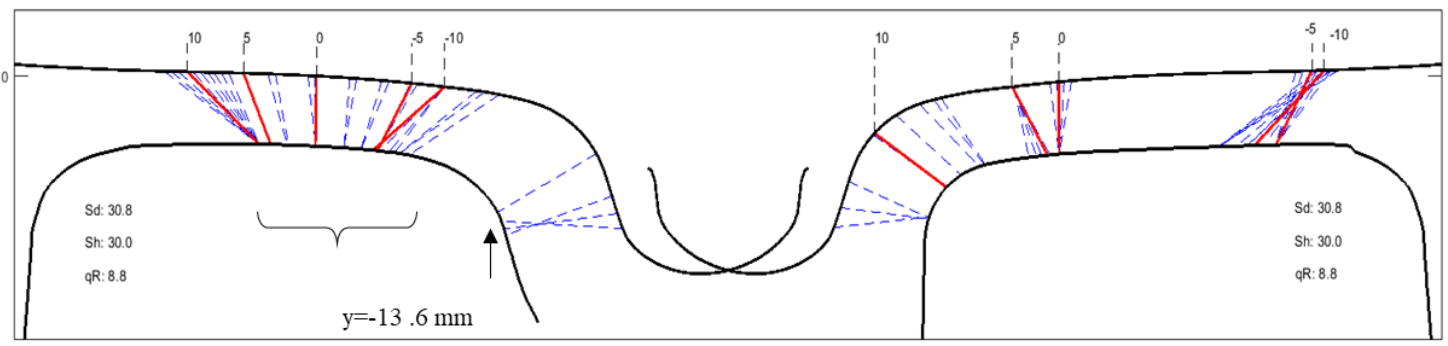

c) $\mathrm{R}=653 \mathrm{~m}$ kurptaki ray $-\mathrm{Aşs}$ mmış tekerlek

Ekartman Uzunluğu: $1600 \mathrm{~mm}$ İç Aç1klık= $1522.5 \mathrm{~mm}$

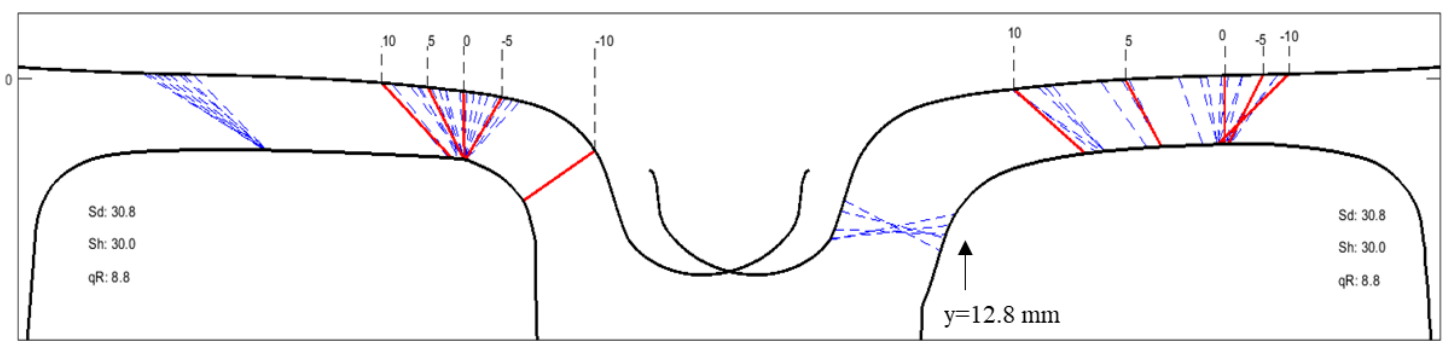

Şekil 8. Yeni ve aşınmış durumunda ray ve tekerlek (olası) temas noktaları (Sh: buden yüksekliği, Sd:buden kalınlığı ve qR:buden açısı)

\subsection{Temas parametreleri}

Temas noktaları parametreleri yukarıda Şekil 4'de verilen Hertzian teorisi iligili formüller [11] kullanılarak hesaplanmıştır. Temas yüzey alanı (A), boyuna genişlik (a), yanal genişlik (b), eliptikliği $(\mathrm{a} / \mathrm{b})$ ve maksimum temas basınc1/gerilimi $\left(P_{m}\right)$ değerleri farklı yanal yer değiştimeler altında Tablo 2'de verilmektedir. Tasarım ve işletme durumundaki profiller altında tekerlek taban ve buden noktalarında oluşabilecek farklıları göstermek amacıyla iki farklı yanal yerdeğiştirme değeri ele alınmıştır. 
Yeni ray-tekerlek profilleri durumunda, $\mathrm{y}=6.3 \mathrm{~mm}$ buden başlangıç temas noktası dikkate alınarak, $y=2.5 \mathrm{~mm}$ ve $y=7.5 \mathrm{~mm}$ 'de temas değerleri verilmiştir. Değerler incelendiginde, $y=$ $2.5 \mathrm{~mm}$ 'de tekerlek taban ve ray mantarı üzerinde oluşabilecek temas noktasının $\mathrm{y}=7.5 \mathrm{~mm}$ 'de tekerlek budeni-ray yanak bölgesi temasına göre daha küçük yüzey alanına sahip olduğu ve bu sebeple de daha fazla gerilme meydana geldiği gözükmektedir.

Benzer şekilde, işletme altında aşınmış profiller kullanılarak buden temas noktası başlangıç değerleri dikkate alındığında $\mathrm{y}= \pm 5 \mathrm{~mm}$ ve $\mathrm{y}= \pm 15 \mathrm{~mm}$ yanal yerdeğiştimeler altında temas parametreleri hesaplanmıştır. Tasarım'daki yeni profillerden farklı olarak tekerlek budeni ray yanağında daha küçük temas yüzeyi oluşturduğu ve böylelikle daha yüksek gerilmelerin oluştuğu görülmektedir. Örneğin, $653 \mathrm{~m}$ yarıçaplı kurpta oluşan yüksek basınç değeri $\left(P_{m}=4576.2 \mathrm{~N} / \mathrm{mm}^{2}\right)$ aşınmayı daha da arttıracağı anlaşılmaktadır. Bu durum işletmede aşınmış olan profiller altında tasarım profiline oranla daha konformal olmayan temas noktaları oluşturabileceğini göstermektedir. Fakat ilerleyen zamanla aşınmaların artmasıyla (örneğin, $130 \mathrm{~m}$ yarıçaplı kurp) ray-tekerlek etkileşiminin daha uygun duruma geçebileceği ve maksimum basınçta $\left(P_{m}=3220.5\right.$ $\mathrm{N} / \mathrm{mm} 2$ ) azalmaya sebep olabileceği düşünülebilir. Bu durumun aşınma limit durumlarının (çok) öncesinde gerçekleştiği, limit değerlerine yaklaşıldığı takdirde gerekli bakım çalışmalarının yapılması gerektiği unutulmamalıdır.

Tablo 2'de verilen değerler tek temas noktası prensibine dayanmaktadır. Daha hassas temas noktaları analizi hesaplayabilmek için detaylı dinamik tren modelleri oluşturulduktan sonra hat üzerinde simülasyonlarının yapılması gereklidir.

Tablo 2. Yeni ve aşınmış durumunda ray ve tekerlek profilleri altında oluşan temas parametreleri değerleri

\begin{tabular}{lcccccc}
\hline \multirow{2}{*}{$\begin{array}{c}\text { Temas } \\
\text { Parametreleri }\end{array}$} & \multicolumn{2}{c}{ Yeni ray - tekerlek } & \multicolumn{4}{c}{ Aşınmış ray ve tekerlek } \\
\cline { 4 - 7 } & \multicolumn{2}{c}{} & & $\mathrm{R}=130$ m kurptaki ray & \multicolumn{2}{c}{$\mathrm{R}=653$ m kurptaki ray } \\
\hline $\mathrm{y}(\mathrm{mm})$ & 2.5 & -5.0 & -15.0 & 7.5 & 5.0 & 15.0 \\
\hline $\mathrm{a}(\mathrm{mm})$ & 7.18 & 8.14 & 8.5 & 6.61 & 7.31 & 9.45 \\
\hline $\mathrm{b}(\mathrm{mm})$ & 2.42 & 1.36 & 1.15 & 3.42 & 1.61 & 0.62 \\
\hline$(\mathrm{a} / \mathrm{b})$ & 2.97 & 5.99 & 7.39 & 1.93 & 4.54 & 15.24 \\
\hline $\mathrm{A}\left(\mathrm{mm}^{2}\right)$ & 54.59 & 34.78 & 30.71 & 71.02 & 36.97 & 18.41 \\
\hline $\mathrm{P}_{\mathrm{m}}\left(\mathrm{N} / \mathrm{mm}^{2}\right)$ & 3771.2 & 2848.8 & 3220.5 & 2898.6 & 2292.4 & 4576.2 \\
\hline
\end{tabular}

\section{Yorumlar}

Demiryollarında varlık yönetimi, tüm alt sistemlerdeki varlıkların ömür maliyetlerinin optimizasyonu ile ilgilenmektedır. Bu sebeple, tasarımdan başlayarak işletme, bakım ve tasfiye aşamalarına kadar uzanan süreçte varlıkların ömürleri efektif olarak planlanmalı ve gerekli bakım çalışmaları sürdürülmelidir.

Varlık yönetimi altında ray-tekerlek etkileşimi detaylı simülasyon ve modelleme yöntemleri kullanılarak uygun profil ve malzeme seçimi ve bakım sürelerinin optimizasyonu yapılmaktadır. Fakat, bu tür çalışmalar ilave zaman ve maliyet gerektireceği için öncellikle öncül analizlerle raytekerlek etkileşimindeki hasar ve aşınma durumlarına olan yatkınlığın gösterilmesi daha iyi olacaktır.

Bu çalışmada, öncül ray-tekerlek etkileşimi analizi Avrupa Altyapı Yöneticisi’ne ait tasarım (yeni) ve işletme (aşınmış) altındaki profilleri kullanılarak değerlendirilmiştir. Raylarda CEN 54E1 (1:40) profili ile elektrikli tren dizilerine ait özel tekerlek profili kullanılmıştır. Bakım ve 
yenileme için gerekli olan profillerdeki aşınma ölçümlerinden farklı değerlere sahip ray ve tekerlek profilleri seçilerek temas analizleri hesaplanmıştır.

İlk adımda, işletme altındaki ray ve tekerlek profillerindeki değişimi gözlemlemek amacıyla tasarım (yeni) profil ile karşılaştırılmıştır. Tren dinamik kurp performansı etkisiyle, yüksek raylarda ekartman köşesi ve yanak bölgelerinde daha fazla aşınmanın meydana geldiği düşük raylarda ise ray mantarı üzerinde daha az oranda aşınmanın gerçekleştiği gözlemlenmiştir. Ray yenileme tarihi bilinmemesine karşın literatür araştırmasından da beklenildiği üzere küçük yarıçaplı kurp bölgelerinde daha fazla aşınma olduğu tespit edilmiştir.

İkinci adımda hesaplanan YYF, tren dinamik hareketi, eşdeğer koniklik ve olası oluşabilecek temas noktaları hakkında işaretler vermektedir. Tasarım durumunda YYF doğrusunun eğiminindeki düşüklük ve eşdeğer konikliğin de işletme altındaki duruma oranla daha küçük olduğu hesaplanmıştır. Düşük YYF doğrusu eğimindeki ani sıçrama, buden temas başlangıç noktası olarak değerlendirilmekte olup, $\mathrm{y}= \pm 6.30 \mathrm{~mm}$ yanal yer değiştirmede gerçekleşmiştir. İşletme altındaki durumda YYF doğrusu eğiminin ve eşdeğer konikliğin yükseldikleri ve verilen $130 \mathrm{~m}$ yarıçaplı kurp bölgesinden alınan ölçümlerde en yüksek 0.29 değerine ulaştığ 1 gözlemlenmiştir.

Farklı yanal yer değiştirmeler altında oluşturulan temas noktaları grafiklerinde, YYF doğruları eğimlerinden de beklenildiği üzere yeni ve $653 \mathrm{~m}$ yarıçaplı kurp durumlarında temasların ray mantarı ve yanak bölgelerinde daha küçük alanlarda kümelendiği fakat, daha küçük yarıçaplı 130 m'lik (yüksek aşınma) kurp altında temas noktalarının daha geniş alana yayıldığı gözlemlenmiştir. $\mathrm{Bu}$ durum, tasarım ve az aşınmış koşullardaki ray ve tekerlek etkileşiminin konformal olmayan ikili temasa daha yatkın olduğunu işaret etmiştir.

Dördüncü adımda Hertz teorisi yardımıyla hesaplanan temas parametrelerinde temas yüzey alanı (A), boyuna genişlik (a), yanal genişlik (b), eliptikliği (a / b) ve maksimum temas basıncı / gerilimi $P_{m}$ değerleri hesaplanmıştır. Tekerlek taban ve buden temasındaki farklılıkları gösterebilmek amacıyla iki yanal yerdeğiştirme altında değerler gösterilmiştir. Yeni durumda tekerlek buden temasının daha geniş bir alana etki ettiği ve böylelikle maksimum basıncın da daha düşük olduğu gözlemlenmiştir. Tekerlek ve ray ömür başlangıcında profillerin istenen konformal seviyede olmaması sonucunda maksimum basıncın 653 m yarıçaplı kurpta en yüksek $P_{m}=4576.2$ seviyeye çıktı̆̆ tespit edilmiştir. Fakat, aşınmaların artmasıyla ray ve tekerlek etkileşimi daha uygun koşullara geçtiği, $\mathrm{R}=130 \mathrm{~m}$ yarıçaplı kurpta oluşan maksimum basınç değerindeki azalmadan da görülmektedir. Ama yine de, bu durumun aşınma limit durumlarının (çok) öncesinde gerçekleştiği, limit değerlerine yaklaşıldığı takdirde gerekli bakım çalışmalarının yapılması gerektiği unutulmamalıdır.

Sonuç olarak, tasarımdaki tekerlek ve ray profil seçiminin daha az YYF doğru eğimine ve eşdeğer konikliğe sahip olduğu ve bu durumun daha yüksek temas basıncına yol açabileceği gözlemlenmiştir. Bu durumun aşınma ve hasar başlama oluşumlarının daha erken olabilmesine sebep verebilmektedir. İşletme durumunda aşınmalardaki artı̧̧ sayesinde ray-tekerlek etkileşimi optimizasyonun sağlanabileceği ve temas basıncı değerlerinin düşmesiyle aşınma ve hasar durumlarına olan yatkınlıkta azalma görülebileceği düşünülebilir. Bu durumun varlıkların ömürlerinin uzamasına yardımcı olacağı da söylenebilir.

Öncül analizde aşınma ve hasar durumlarına olan yatkınlık ray-tekerlek etkileşimi uygunluğu ve işletmede tasarıma oranla nasıl farklılıklar meydana gelebileceği hakkında bilgiler verirken varlıkların ömür maliyetlerinin hesaplanabilmesi için çeşitli simülasyon ve modelleme yöntemleri kullanılarak detaylı temas analizleri yapılması gerekmektedir. Şekil 9'da detaylı temas analizlerinde ele alınan tren, ray-tekerlek etkileşimi, hat kaynaklı etkenler verilmektedir [12]. 
Buradan da anlaşılacağı üzere tasarım aşamasından başlayarak tren dinamik araç modelleri oluşturulmalı ve planlanan hat güzergahında simülasyon işlemleri gerçekleştirilmesi temas noktalarının ve ilgili parametrelerinin daha hassas hesaplanmasına yardımcı olacaktır. Ray ve tekerlek ömür maliyetlerini optimize edebilmek amaciyla farklı profil tipleri ve malzemeler kullanılarak parametre değerleri karşılaştırılabilinirken aşınma ve yorulmaya bağlı kusur tahmin modelleri kullanılarak da yapılan daha detaylı çalışmalar, bakım sürelerinin planlanmasına yardımcı olabilmektedir.

- Tren ağırlığ1

- Birincil süspansiyon sapma rijitliği

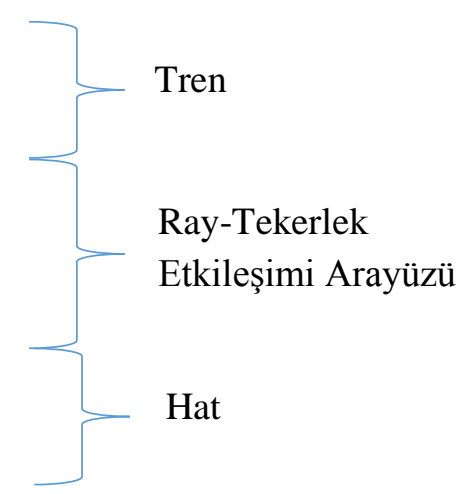

- Hiz

- Koniklik

- Sapma açıs1

- Yanal yerdeğiştirme

- Sürtünme katsayis1

- Kurp eğriliği

- Dever

- Hat geometrisi düzensizlikleri

Şekil 9. Detaylı temas analizinde ele alınan tren, ray-tekerlek etkileşimi ve hat kaynaklı etkenler [12]

Halihazirda işletme altındaki hatlarda da yukarıda verilen faktörlerin ray ve tekerlek temasına etkisi incelenebilir. Farklı hız ve yağlama (sürtünme katsayısı) altında temas noktaları analizlerinin yanında, tren stabilitesi ve derayman yatkınlığı da bulunması gereklidir. Düşük eşdeğer koniklik değerinin buden temasına daha yatkın olduğu belirtilmesine karşın farklı hızlar altında trenin stabilitesine etkisi de mutlaka incelenmelidir.

\section{Kaynakça}

[1] A. Ekberg, A, Bengt, E. Kabo, "Wheel/rail rolling contact fatigue-Probe, predict, prevent." Wear, vol. 314.1-2, 2014, 2-12.

[2] B. Dirks, R. Enblom, A. Ekberg, M. Berg, "The development of a crack propagation model for railway wheels and rails." Fatigue \& Fracture of Engineering Materials \& Structures, vol 38.12, 2015, 14781491.

[3] T. Jendel, "Prediction of wheel profile wear-comparisons with field measurements." Wear, vol 253.1-2, 2002, 89-99.

[4] W. Schoech, R. Heyder, R. Dollevoet. "Specific railhead profiles to control rolling contact fatigue,design and maintenance, the European approach." 8th International Conference on Contact Mechanics and Wear of Rail/Wheel Systems (CM2009). CM2009, 2009.

[5] U. Olofsson, Y. Zhu, A. Saeed, R. Lewis, S. Lewis, "Tribology of the wheel-rail contact-aspects of wear, particle emission and adhesion," Vehicle System Dynamics, vol. 51, no. 7:1091-1120, 2013.

[6] M. Asplund, M. F. Stephen, W. Schoech. "A Nordic heavy haul experience and best practices," Proceedings of the Institution of Mechanical Engineers, Part F: Journal of Rail and Rapid Transit, vol. 231, no. 7:794-804, 2017.

[7] B. Dirks, R. Enblom, "Prediction model for wheel profile wear and rolling contact fatigue," Wear, vol. 271, no. 1-2: 210-217, 2010.

[8] Railway applications. Method for determining the equivalent conicity, BS EN 15302, 1st ed. Brussels: CEN; 2008

[9] H. Hertz, "On the contact of rigid elastic solids and on hardness," In: Schott, J.A. (Ed.), Miscellaneous papers by H. Hertz. MacMillan, London, pp. 164-183

[10] S. Iwnicki, Handbook of railway vehicle dynamics. Boca Raton: CRC/Taylor \& Francis, 2006 
[11]I, Sebesan, Z. Yahia, "Determination of wheel-rail contact characteristics by creating a special program for calculation." Mathematical Modelling in Civil Engineering vol. 10.3: 48-59, 2014.

[12]I. Y. Shevtsov, PhD Thesis 'Wheel/rail interface optimisation', Delft University of Technology, 2008.

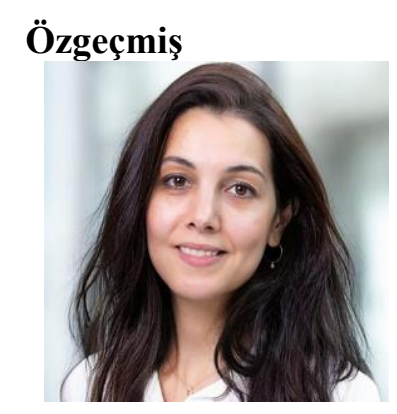

Beyanlar:

Bu makalede bilimsel araştırma ve yayın etiğine uyulmuştur.

\section{Pelin BOYACIOĞLU}

Yıldız Teknik Üniversitesi İnşaat ve Harita Mühendisliği bölümlerinden mezun olduktan sonra yüksek lisansını Boğaziçi Üniversitesi'nde ulaştırma ve trafik mühendisliği alanlarında tamamlamıştır. Doktara eğitimini İngiltere'de Huddersfield Üniversitesi, Demiryolu Araştırmaları Enstitüsü'nde tamamlamış ve daha sonrasında hat ve tren bakım optimizasyonları konularında çeşitli akademik ve endüstriyel danışmanlık projelerinde yer almıştır. Halen, Imperial College London Üniversitesi'nde araştırmacı ve demiryolu varlık yönetimi uzmanı olarak çalışmaktadır.

E-Posta: p.boyacioglu@imperial.ac.uk 